\title{
Regenerating Afferent Fibers Stimulate the Recovery of Mauthner Cell Dendritic Branching in the Axolotl
}

\author{
Linda A. Goodman, David A. Covell, Jr., and Pat G. Model \\ Department of Neuroscience, Rose F. Kennedy Center for Research in Mental Retardation and Human Development, \\ Albert Einstein College of Medicine, Bronx, New York 10461
}

In the medulla of the axolotl (Ambystoma mexicanum), Mauthner cells (M-cells) occur as a pair of large identifiable neurons at the level of entry of the vestibular nerve (nVIII). Each receives synapses from the ipsilateral nVIII; the terminals can be identified as club endings and are restricted to a specific set of M-cell dendritic branches. We have examined these branches for morphologic changes following long-term deafferentation in the presence and absence of nerve regeneration. Deafferentation was brought about in a group of young larvae by unilaterally severing $n$ VIII. The nerve was allowed to regenerate in half of the larvae. In those remaining, the nVIII ganglion was damaged to preclude or limit nerve regeneration. The contralateral side served as control. After 3 months survival, the larvae were killed and the medullae prepared for microscopy. To estimate the extent of nerve regeneration, axons in the experimental nVIII tract were counted and compared with the number in the control. The mean number of axons in the $\mathrm{nVIII}$ tract ipsilateral to intact ganglia indicated that $69 \%$ of the fibers had regenerated. In contrast, only $31 \%$ regenerated in larvae with damaged ganglia. Electron microscopic analysis of selected sections revealed that the mean number of $n \mathrm{VIII}$ terminals per section through $\mathbf{M}$-cells ipsilateral to destroyed ganglia was significantly less than the mean number in analogous sections through either control cells or cells ipsilateral to intact ganglia. Control and experimental $\mathbf{M}$-cells were reconstructed from serial sections. Deprived M-cells had significantly reduced dendritic branching patterns in the region that normally receives $\mathrm{nVIII}$ input. On the other hand, the extent of branching on cells receiving regenerated afferents from intact ganglia was like that of their contralateral controls. The distribution of dendritic branches on many reinnervated $\mathbf{M}$-cells, however, was broader than that on control cells. Electron microscopic examination of the displaced dendritic branches (those extending into adjacent tracts)

\footnotetext{
Received Sept. 14, 1987; revised Dec. 21, 1987; accepted Dec. 22, 1987.

We wish to thank Sarah Wurzelmann for the electron microscopy and for her expert preparation of publication prints. We also thank Kathleen Tinglin for her fine technical assistance and Joseph Cubells for his help with the statistical analysis.

The work reported here is from a thesis to be submitted in partial fulfillment of the requirements for the Degree of Doctor of Philosophy in the Sue Golding Graduate Division of Medical Sciences, Albert Einstein College of Medicine, Yeshiva University.

This work was supported in part by NIH Traing Grant T32GM7288 and by U.S. Public Health Service Grant NS-18823.

Correspondence should be addressed to Linda A. Goodman, Department of Neuroscience, Rose F. Kennedy Center, Box 33, Albert Einstein College of Medicine, 1410 Pelham Parkway South, Bronx, NY 10461.

Copyright (C) 1988 Society for Neuroscience $0270-6474 / 88 / 083025-10 \$ 02.00 / 0$
}

revealed that they received vestibular synapses. Thus, in some animals, regenerated vestibular fibers were not restricted to the $\mathrm{nVIII}$ tract.

Deafferentation of the $\mathrm{M}$-cell results in a reduction of dendritic branches in the region deprived of vestibular contacts. Restoration of the branches occurs only when $\mathrm{nVIII}$ terminals reestablish contact with the $\mathrm{M}$-cell. These data indicate that regenerating afferents stimulate dendritic growth and that afferent innervation is essential in maintaining the dendritic branching pattern of target neurons.

Afferent innervation affects the properties of target neurons: for example, during development, ingrowing axons are important in regulating the elaboration of normal dendritic arborizations by postsynaptic neurons (e.g., Morest, 1969; Rakic, 1972; Goodman and Model, 1988). The present work examines the influences underlying the subsequent maintenance of dendritic branching patterns. In the past, the role of afferent input has been studied by interrupting a source of innervation and, at a later time, examining the postsynaptic target neurons for morphologic changes. A majority of the results indicate that afferent innervation is critical in the ongoing growth and maintenance of normal dendritic patterns: deafferentation reduces the length (Larsell, 1931; Murphey et al., 1975), alters the branching pattern (Jones and Thomas, 1962), and produces atrophy (Benes et al., 1977; Deitch and Rubel, 1984) of postsynaptic dendrites. Several studies of central neurons have shown that ablating a source of afferents early in the neonatal period or in adults produces dendritic growth into abnormal regions of neuropil (in kittens, Smith, 1974; in neonatal mice, Harris and Woolsey, 1981; in adult rats, Caceres and Steward, 1983): the new dendritic branches on deafferented neurons were oriented toward areas of other viable afferent fibers. At odds with these data are reports that removal of preganglionic innervation of mammalian superior cervical ganglion cells has little effect on postsynaptic dendritic geometries (McLachlan, 1974; Smolen and Beaston-Wimmer, 1986; Voyvodic, 1987). In the present study, we have examined the long-term effects of partial deafferentation on an identified neuron, the Mauthner cell (M-cell). In addition, we have analyzed the response of the M-cell to reinnervation.

In a system where the postsynaptic target is an identified neuron, specific morphologic changes brought about by the removal of an afferent source are readily defined. The $\mathrm{M}$-cell, medulla and related structures in $21 \mathrm{~mm}$ axolotl (Ambystoma mexicanum) larvae have been described previously (Goodman and Model, 1988). In the older larvae used in the present experiment, M-cells are larger and have more complex branching 
A
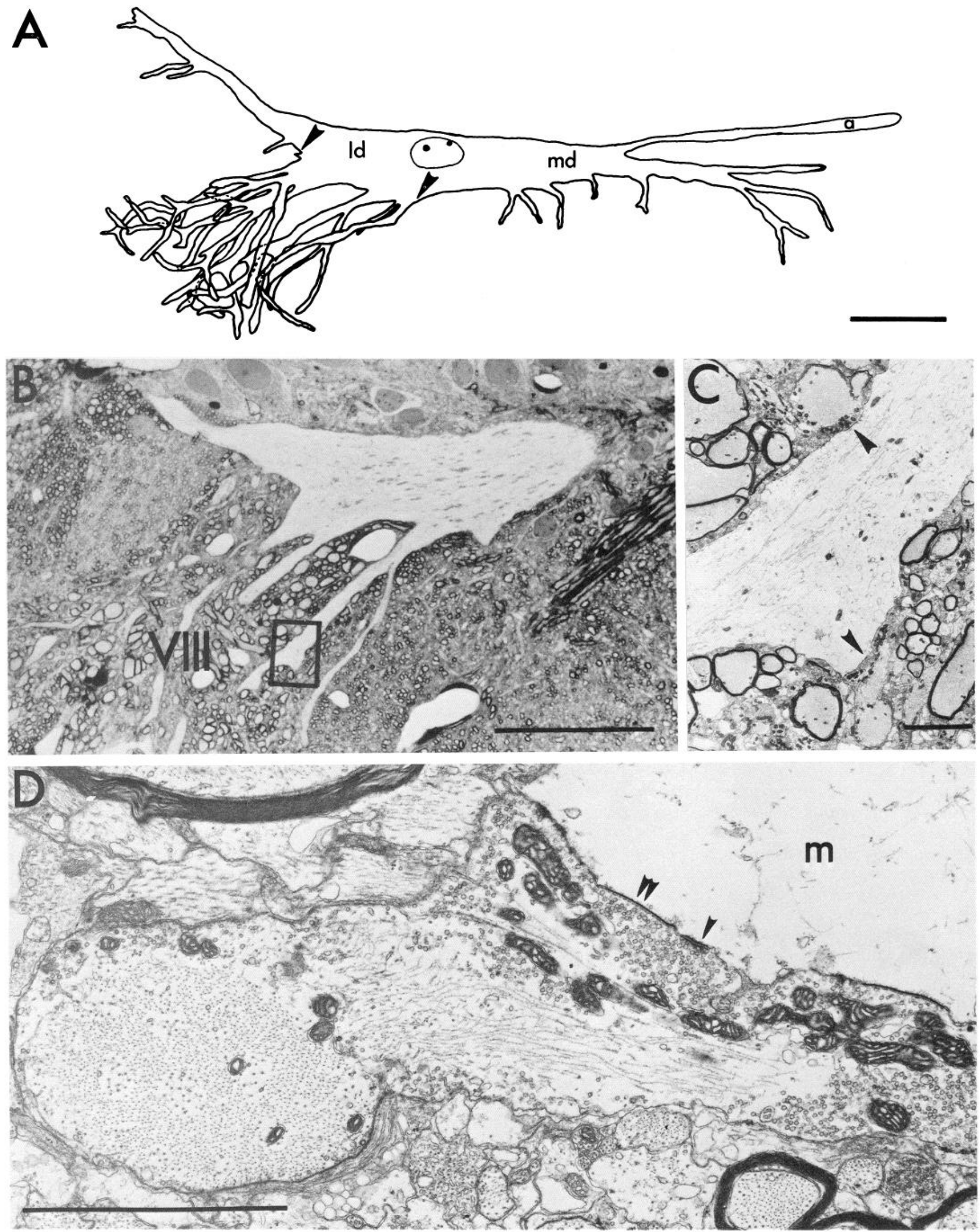

Figure 1. A, Perimeter of an M-cell reconstructed from serial cross sections through the medulla of a $12 \mathrm{~cm}$ larva. The axon $(a)$ and medial dendrite $(m d)$ project to the right; the lateral dendrite $(l d)$, to the left. Branches projecting from the ventral border of the lateral dendrite (between 
patterns, but the general relationships are the same. The salient features are (1) M-cells are easily identified as a single pair of largc ncurons in the medulla at ear level (Herrick, 1914); (2) they are interneurons important in integrating the escape reflex; (3) each is bipolar, a large dendrite projecting from the medial pole of the soma and another from the lateral pole (Fig. 1A); (4) a localized group of dendritic branches projects from the proximoventral surface of the lateral dendrite (Fig. 1 $A$ ); and (5) these branches receive synapses from the ipsilateral vestibular nerve (Fig. 1, $B, C$ ). Vestibular nerve (nVIII) terminals can be identified in the light microscope (Model, 1978) and confirmed as club endings in the electron microscope (Kimmel and Schabtach, 1974; Model and Wurzelmann, 1982; Fig. 1, C, D, present paper). Following unilateral transection of nVIII, degeneration of vestibular afferents brings about a loss of postsynaptic dendritic surface from the M-cell (D. A. Covell and P. G. Model, unpublished observations). After 4 weeks, nVIII synapses are reestablished on the appropriate region of the cell (Covell and Model, 1984). Here we document the loss of postsynaptic surface over a prolonged period of deprivation and further show that the dendritic branches recover only when reinnervated by regenerating $\mathrm{nVIII}$ axons. Preliminary results of this work have been presented (Goodman and Model, 1986).

\section{Materials and Methods}

The larvae used in these experiments were the product of a single spawning in the axolotl colony maintained in our laboratory. When the larvae reached $3 \mathrm{~cm}$ (about 4 weeks posthatching), each was anesthetized in MS 222 and secured in an operating dish in sterile Niu Twitty's complex salt solution ( $\mathrm{pH} 7.4-7.6)$ with neomycin sulfate $(50 \mathrm{mg} / \mathrm{liter})$. Electrolytically sharpened tungsten needles were used to expose nVIII, and glass needles were used to unilaterally sever the nerve (Covell and Model, 1986). A hooked tungsten needle was passed through the nerve to insure complete transection. The nerve was allowed to regenerate in half of the larvae, and in those remaining, regeneration was prevented or limited by disrupting the nVIII ganglion (Fig. 2): a hooked tungsten needle was used to remove ganglion cells. The contralateral side served as control. The animals were raised in individual dishes at $16^{\circ} \mathrm{C}$.

After 3 months survival, the $11-12 \mathrm{~cm}$ larvae were anesthetized in MS 222 and then perfused with 3\% glutaraldehyde, $2 \%$ paraformaldehyde, $1 \%$ acrolein, and $2.5 \%$ DMSO in $0.1 \mathrm{~m}$ cacodylate buffer ( $\mathrm{pH} 7.4)$ at room temperature. The brain with surrounding tissue was rapidly removed and immersed in the same fixative. After $20 \mathrm{hr}$ at $4^{\circ} \mathrm{C}$, the tissue was washed several times in cacodylate buffer ( $\mathrm{pH} 7.4$; total time, $11 / 2 \mathrm{hr}$ ). The medullae were dissected from the surrounding tissue, postfixed in cold $2 \% \mathrm{OsO}_{4}$ in cacodylate buffer for $2 \mathrm{hr}$, washed in veronal

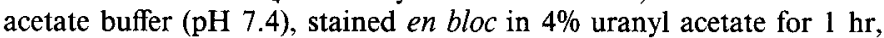
dehydrated in a graded series of ethanols, and embedded in Epon 812. Serial cross sections, $4-\mu \mathrm{m}$-thick, were cut from the medullae, mounted on glass slides, stained with toluidine blue, and photographed in the lighı microscope.

Medullae were examined for evidence of regenerated nVIII axons at the level of the M-cell soma. In light micrographs, the number of large myelinated axons in the nVIII tract was counted as a measure of the extent of vestibular nerve regeneration. The morphology of the M-cell in the operated side was then compared with that of the contralateral control; each cell was represented in a reconstruction derived from light micrographs (methods described previously, Goodman and Model, 1988). Briefly, using aligned micrographs, the perimeter of the cell in
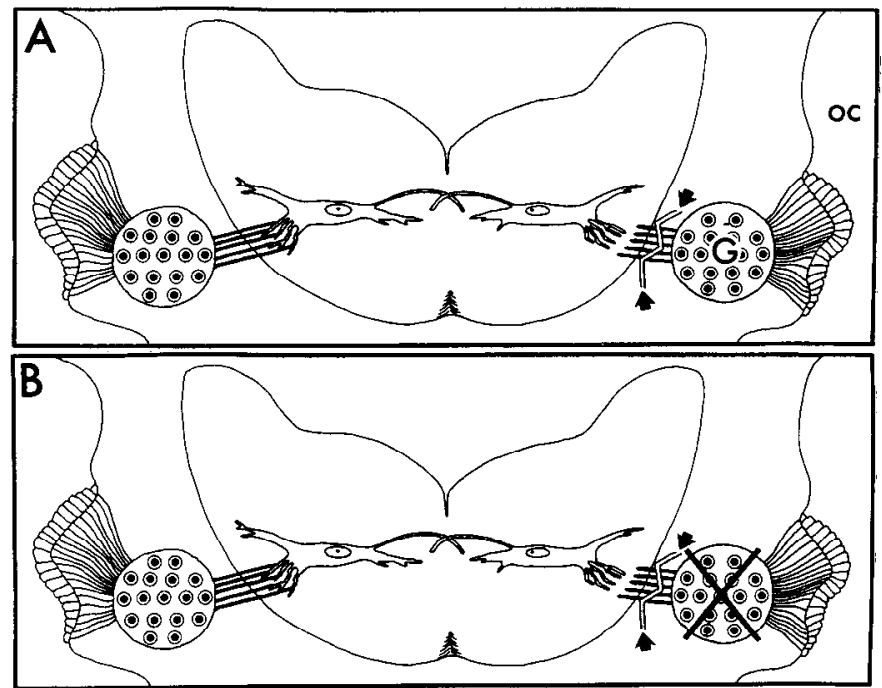

Figure 2. Cartoons of the medulla, nVIII ganglia $(G)$, and otic capsules $(o c)$ in cross section at the level of the M-cells. $A, \mathrm{nVIII}$ was unilaterally severed (between arrows) near its entry into the medulla in $3 \mathrm{~cm}$ larvae. In half of the larvae, the nVIII ganglion was disrupted $(B)$.

successive sections was traced, the contours were superimposed, and the perimeter of the serially reconstructed cell was then traced. After comparing experimental M-cells with their contralateral control, the M-cell pairs in the larvae with intact nVIII ganglia were compared with those in larvae with damaged ganglia.

The region of dendritic surface that normally receives nVIII terminals was examined for the presence of club endings in both the experimental and control sides. Most of the appropriate branches of the lateral dendrite extend ventrolaterally within the nVIII tract as well as caudal to the M-cell soma. To maximize the chance of finding club endings, we analyzed 3 sites of each dendritic tree in regions where the branching was most abundant. In every case, the most rostral of the 3 sections (section A) contained the caudal portion of the M-cell soma, lateral dendrite, and proximal segments of the branches on the lateral dendrite (e.g., Fig. $1 B$ ). Sections $B$ and $C$ were, on average, 10 and $28 \mu \mathrm{m}$ caudal to section A, respectively. Each was mounted onto a blank Epon block and sectioned for electron microscopy. Thin sections were collected on mesh grids, stained with uranyl acetate and lead citrate, and photographed in a Phillips 300 electron microscope. The number of vestibular terminals identified according to criteria described previously (Model and Wurzelmann, 1982) was determined for each of the thick sections by counting them in electron micrographs of representative thin sections. Only terminals with evidence of a synaptic contact (chemical or electrical) were counted (as in Goodman and Model, 1988; Fig. 1D, this paper).

Some of the dendritic branches on the proximoventral surface of the lateral dendrite of several experimental M-cells extended into regions outside of the nVIII tract. These displaced dendritic branches were also examined in the electron microscope to determine whether they received vestibular synapses. Sections $(4 \mu \mathrm{m})$ containing the branches were prepared for electron microscopy.

\section{Results}

The response of the M-cell to deafferentation in the presence or near absence of regenerated afferent contacts was examined.

arrowheads) receive club terminals. Scale bar, $100 \mu \mathrm{m} . B$, Light micrograph of an Epon-embedded, 4- $\mu \mathrm{m}$-thick, toluidinc blue-stained cross section through the M-cell in $A$ showing large branches projecting into the nVIII tract (VIII). Scale bar, $100 \mu \mathrm{m}$. $C$, Low-magnification electron micrograph of the boxed area in $B$. Scale bar, $10 \mu \mathrm{m}$. One of two club endings (arrowheads) is shown at higher magnification in $D$. nVIII terminals are easily identified because they are very large, they make morphologically mixed (chemical and electrical) synaptic contacts, they have mitochondria grouped near the contact region, and they contain densely packed, highly organized neurofilaments. $m$, M-cell; single arrowhead, chemical synapse; double arrowhead, electrical synapse. Scale bar, $5 \mu \mathrm{m}$. 

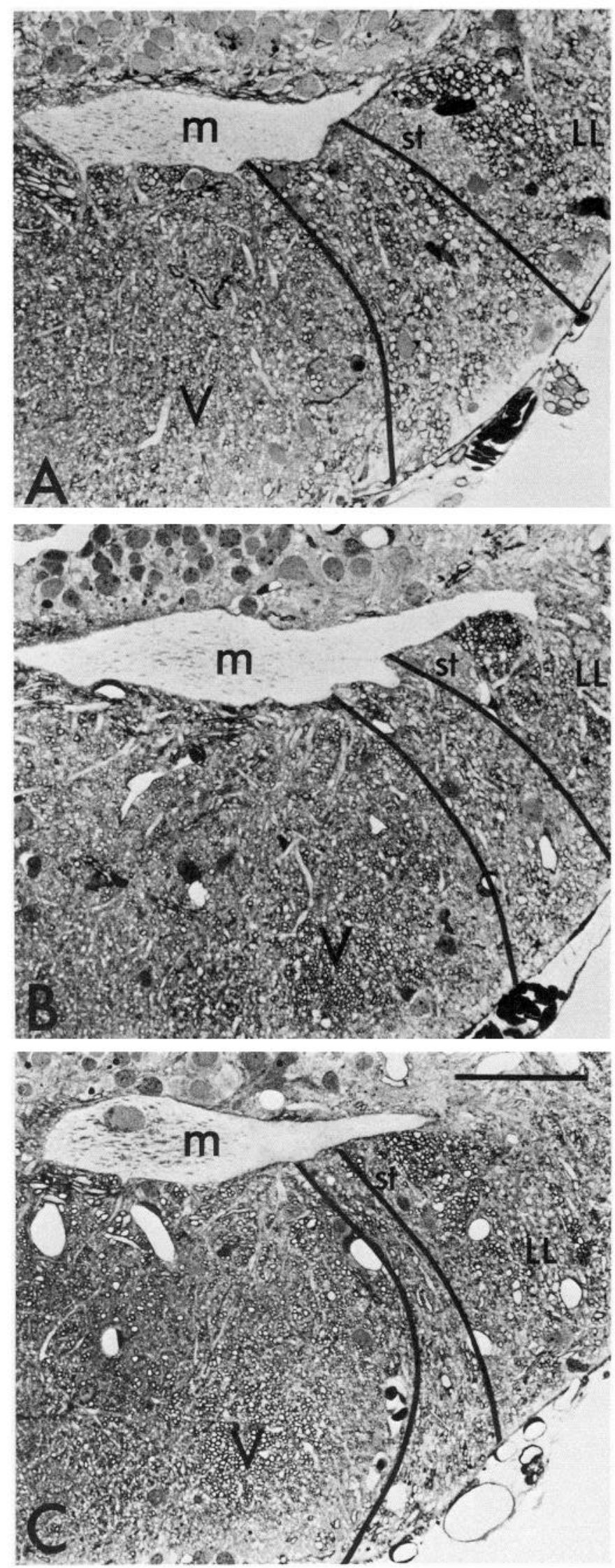

Figure 3. nVIII tracts at M-cell level: regenerated and deprived. A, Cross section through the medulla of a $12 \mathrm{~cm}$ larva with an intact nVIII ganglion, $B$ and $C$, Sections through the medullae of larvae with de-
Table 1. The number of nVIII synapses identified in each $4-\mu \mathrm{m}-$ thick section

\begin{tabular}{lrlrl} 
Treatment & Section A & Section B & Section C & Mean $^{a}$ \\
\hline Control M-cells & & & & \\
1 & 11 & 17 & 10 & 12.3 \\
2 & 9 & 14 & 9 & \\
3 & 15 & 14 & 12 &
\end{tabular}

M-cells ipsilateral to intact ganglia

$\begin{array}{rrrr}1 & 4 & 6 & 2 \\ 2 & 9 & 12 & 8 \\ 3 & 5 & 14 & 13 \\ 4 & 11 & 14 & 8\end{array}$

M-cells ipsilateral to damaged ganglia

$\begin{array}{lllll}1 & 1 & 4 & 4 & 3.8^{b} \\ 2 & 0 & 2 & 2 & \\ 3 & 9 & 8 & 4 & \\ 4 & 3 & 4 & 4 & \end{array}$

The number of club endings in each 4- $\mu \mathrm{m}$-thick section is shown. Three cells in control sides, 4 cells ipsilateral to intact nVIII ganglia, and 4 cells ipsilateral to damaged ganglia were analyzed. Sections A-C pass through analogous sites of each M-cell's dendritic tree.

a Overall mean value for each treatment group.

${ }^{b}$ Mean number of nVIII contacts on deprived cells is significantly less than that on control cells or cells receiving regenerated nerves $(p<0.0001$ and $p<0.001$, respectively, by analysis of variance followed by Newman-Keuls post hoc comparisons).

nVIII was unilaterally transected in 21 larvae and allowed to regenerate in 11 . In the remaining 10 , the vestibular ganglia on the operated side were destroyed. Sixteen larvae survived 3 months to reach $11-12 \mathrm{~cm}$ in length. Of these, the M-cell was absent from the operated side in 4 , and the brain was poorly preserved in 2. Five animals in each experimental group were analyzed. Four of the 5 larvae with intact nVIII ganglia had successfully regenerated nerves (Fig. $3 A$ ) with a mean of 422 axons in the nVIII tract. The fifth larva in that group and the 5 animals with damaged nVIII ganglia had fewer regenerated nVIII axons (mean, 191) ranging from a maximum of 297 (Fig. $3 B$ ) to a minimum of 127 (Fig. $3 C$ ). The mean number of axons in the nVIII tract in the control side of 4 larvae was 614 . Thus, on average, $69 \%$ of the axons regenerated in larvae with intact nVIII ganglia and $31 \%$ in those with disrupted ganglia. A second index for the extent of reinnervation was determined by counting vestibular terminals in three $4-\mu$ m-thick sections through each M-cell's dendritic tree. In both experimental groups, the average number of terminals is proportional to the average number of regenerated axons in the nerve VIII tract: the mean number in sections through M-cells ipsilateral to intact ganglia was $72 \%$ of control, and the mean number in sections through M-cells ipsilateral to damaged ganglia was $31 \%$ of control (Table 1).

The effect of deafferentation on the M-cell in the presence or absence of significant nerve regeneration was evaluated by comparing reconstructed experimental M-cells with the contralateral controls (Figs. 4, 5). Three M-cells deprived of nVIII afferents

stroyed nVIII ganglia. In each micrograph, black lines mark the approximate borders of the nVIII tract. Within the tract, large regenerated vestibular axons are visible in $A$ and a small number are visible in $B$. They are virtually absent in $C . m$, M-cell; $V, \mathrm{nV}$ tract; $s t$, solitary tract; $L L$, lateral line nerve fascicle. Scale bar, $100 \mu \mathrm{m}$. 

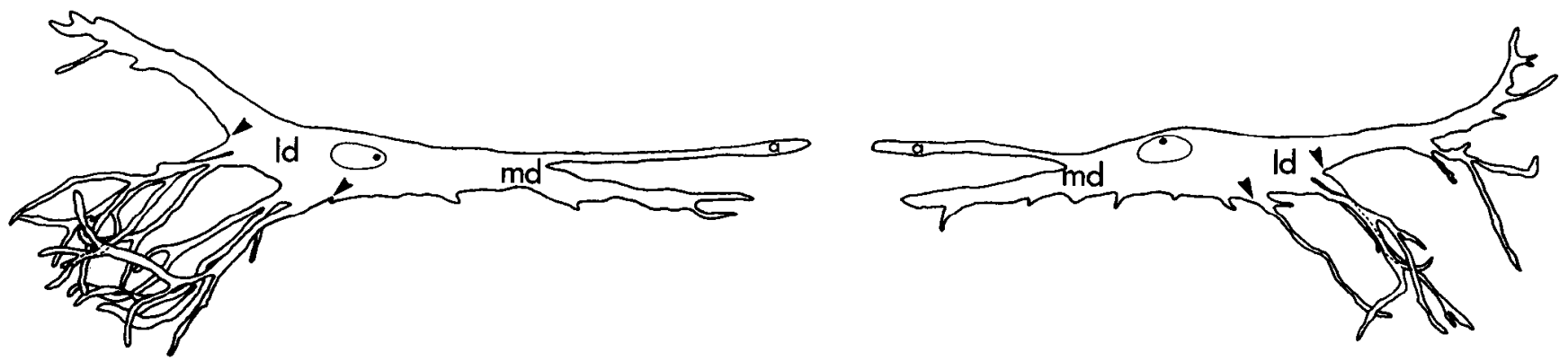

A
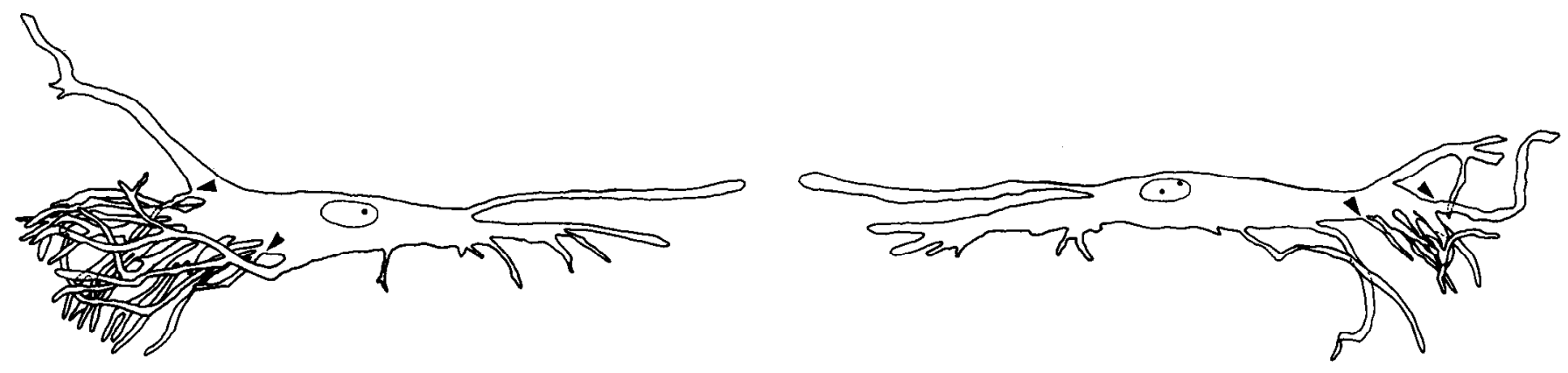

B
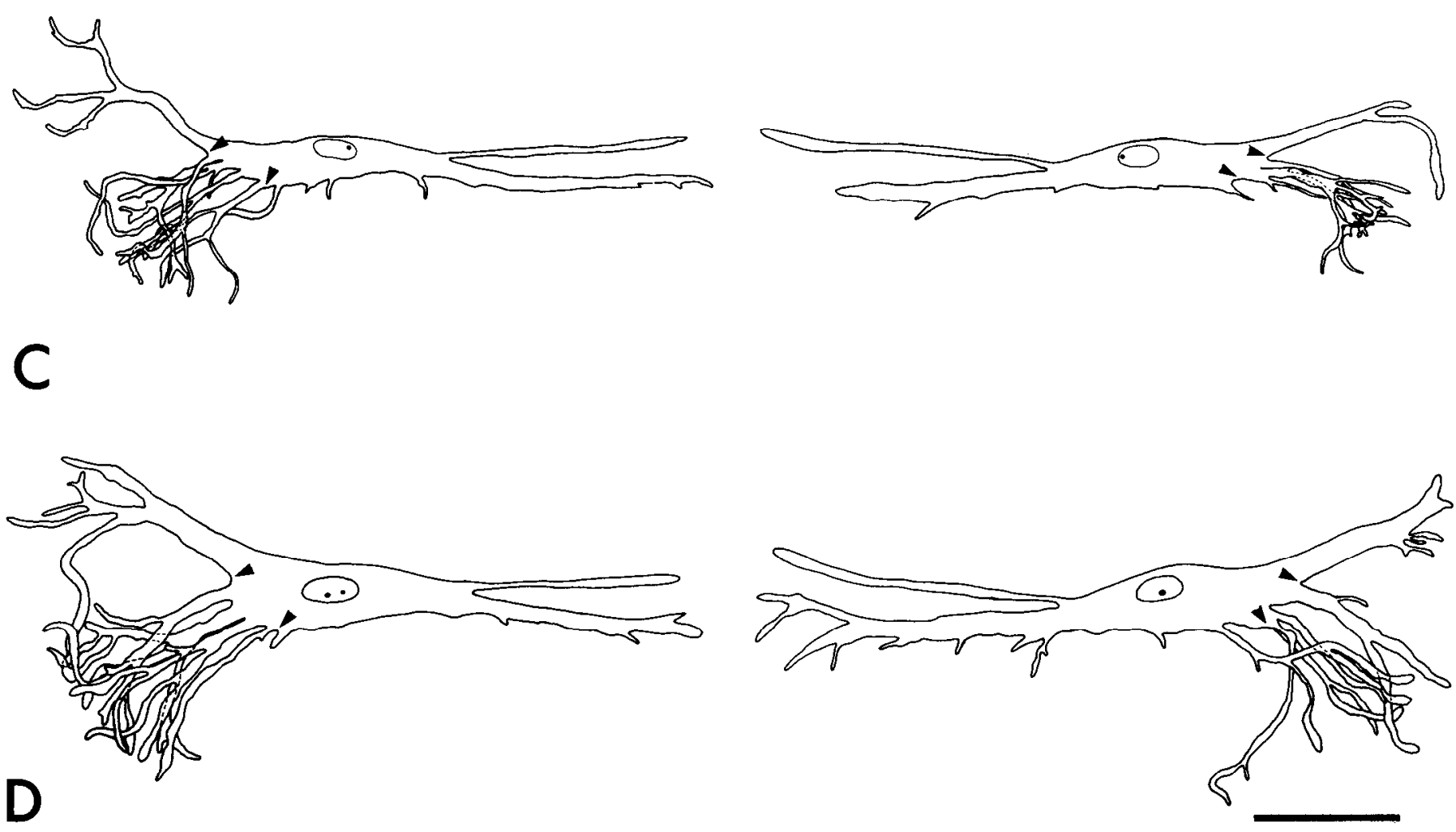

Figure 4. Pairs of reconstructed M-cells in larvae with damaged nVIII ganglia. Control cells are on the left; experimental cells, on the right. The medial dendrite $(m d)$ and axon $(a)$ project towards the center of the page; the lateral dendrite projects toward the side of the page. $A-C$, The experimental cells, deprived of regenerated afferent contacts, have greatly reduced dendritic branching patterns compared with the contralatcral controls (between arrowheads). $D$, The dendritic branching is only moderately reduced in a larva with a partially regenerated nVIII. Scale bar, $200 \mu \mathrm{m}$. 

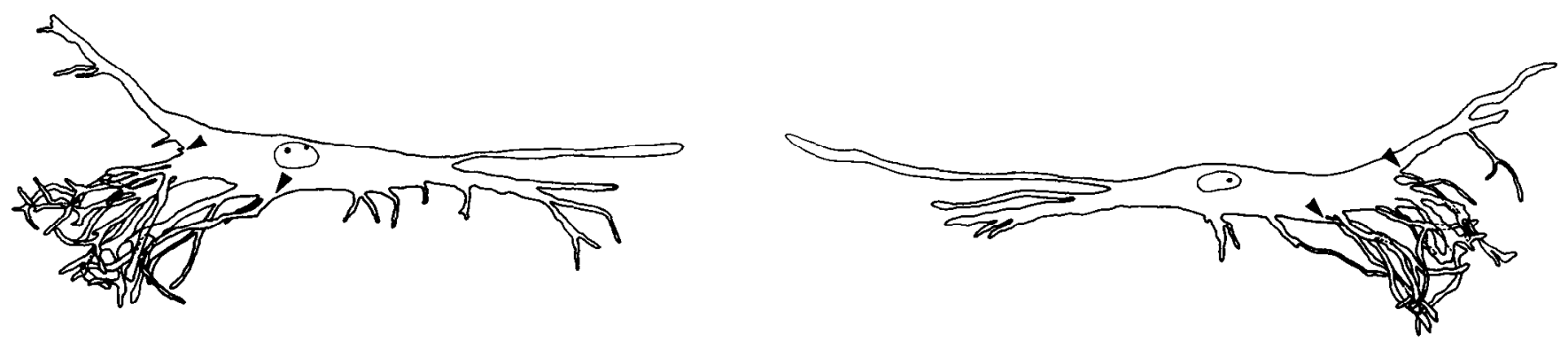

A

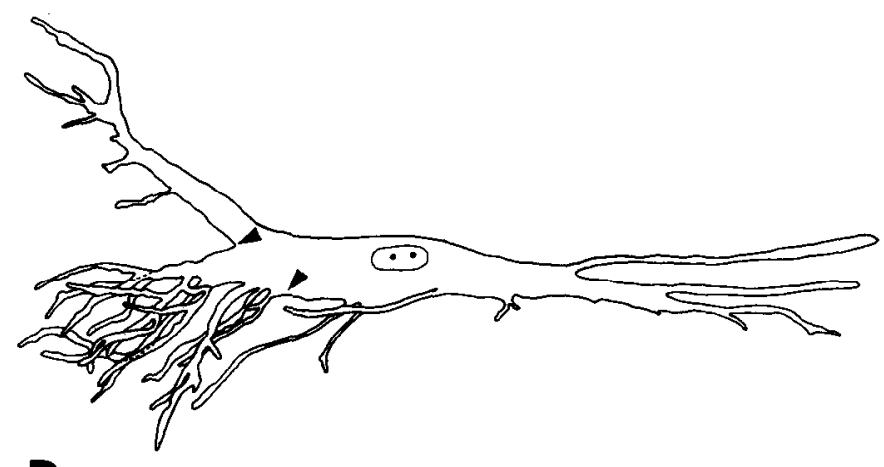

B
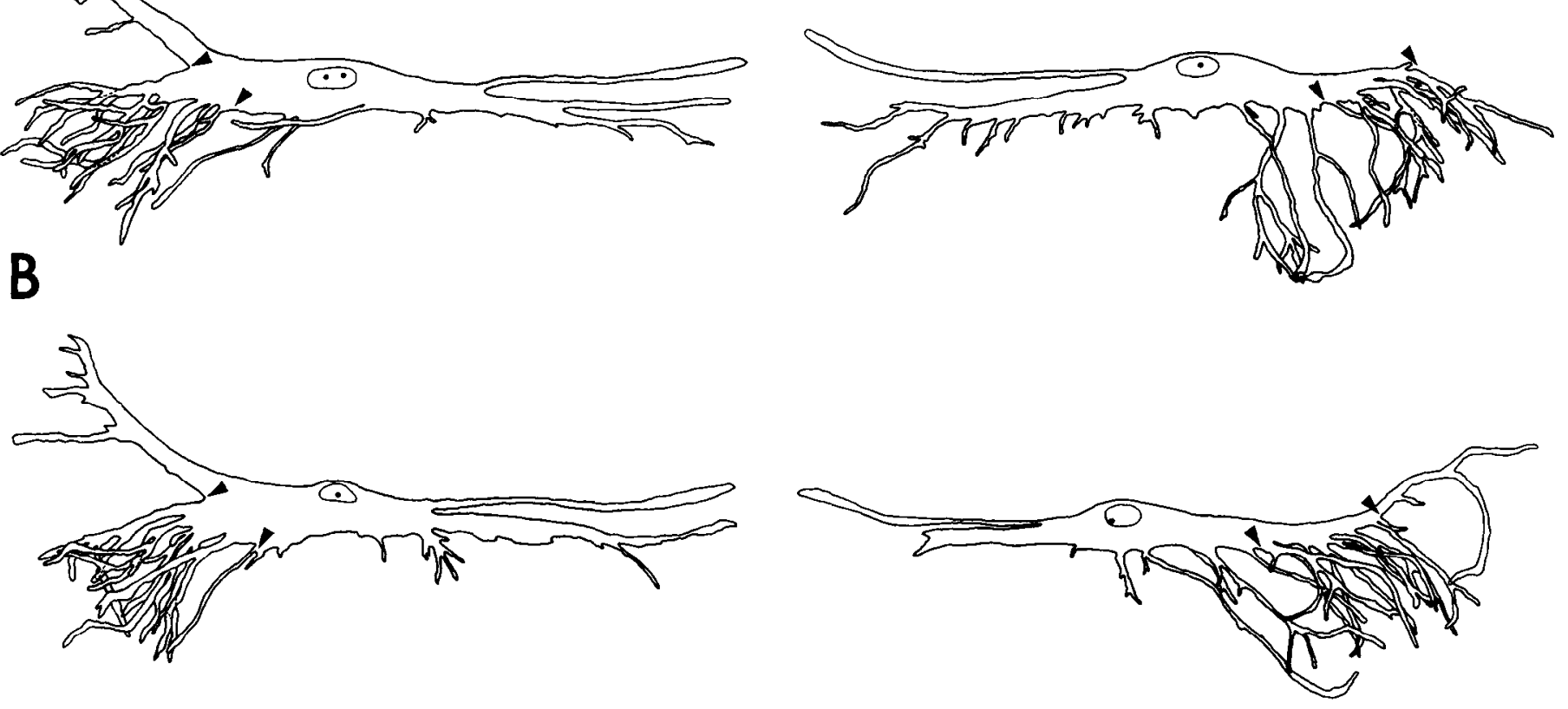

C
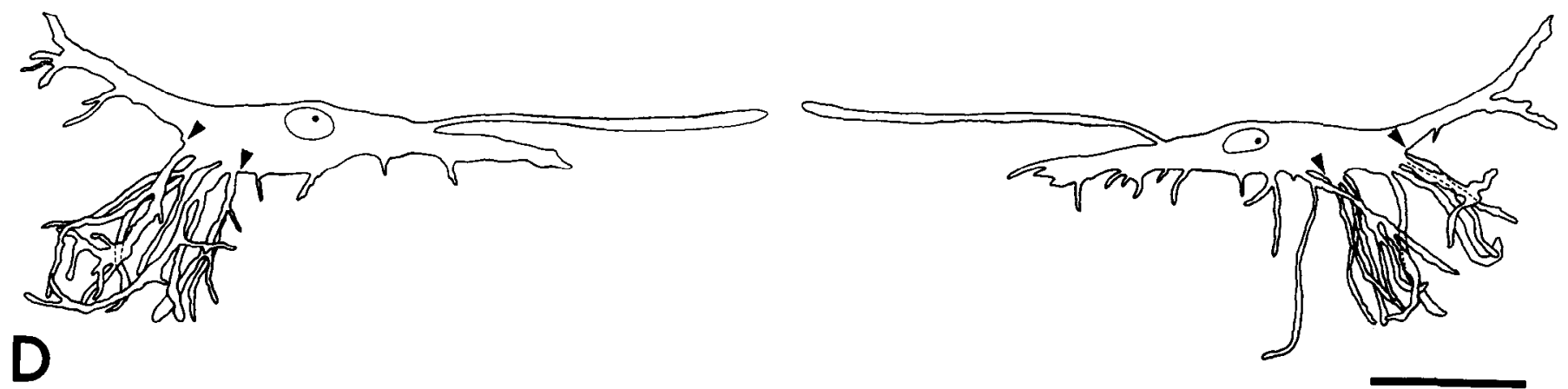

Figure 5. Pairs of reconstructed M-cells in larvae with intact nVIII ganglia. $A-D$, The extent of dendritic branching on experimental cells (right) is like that on control cells (left). However, the distribution of dendritic branches on most of the experimental M-cells is broader than that on controls $(B-D)$. Arrowheads point to the approximate borders of the nVIII tract. Displaced branches project into tracts medial to nVIII. The distal portion of the lateral dendrite of the experimental cell in $B$ is missing; the reason for its absence is not known. Scale bar, $200 \mu \mathrm{m}$. 

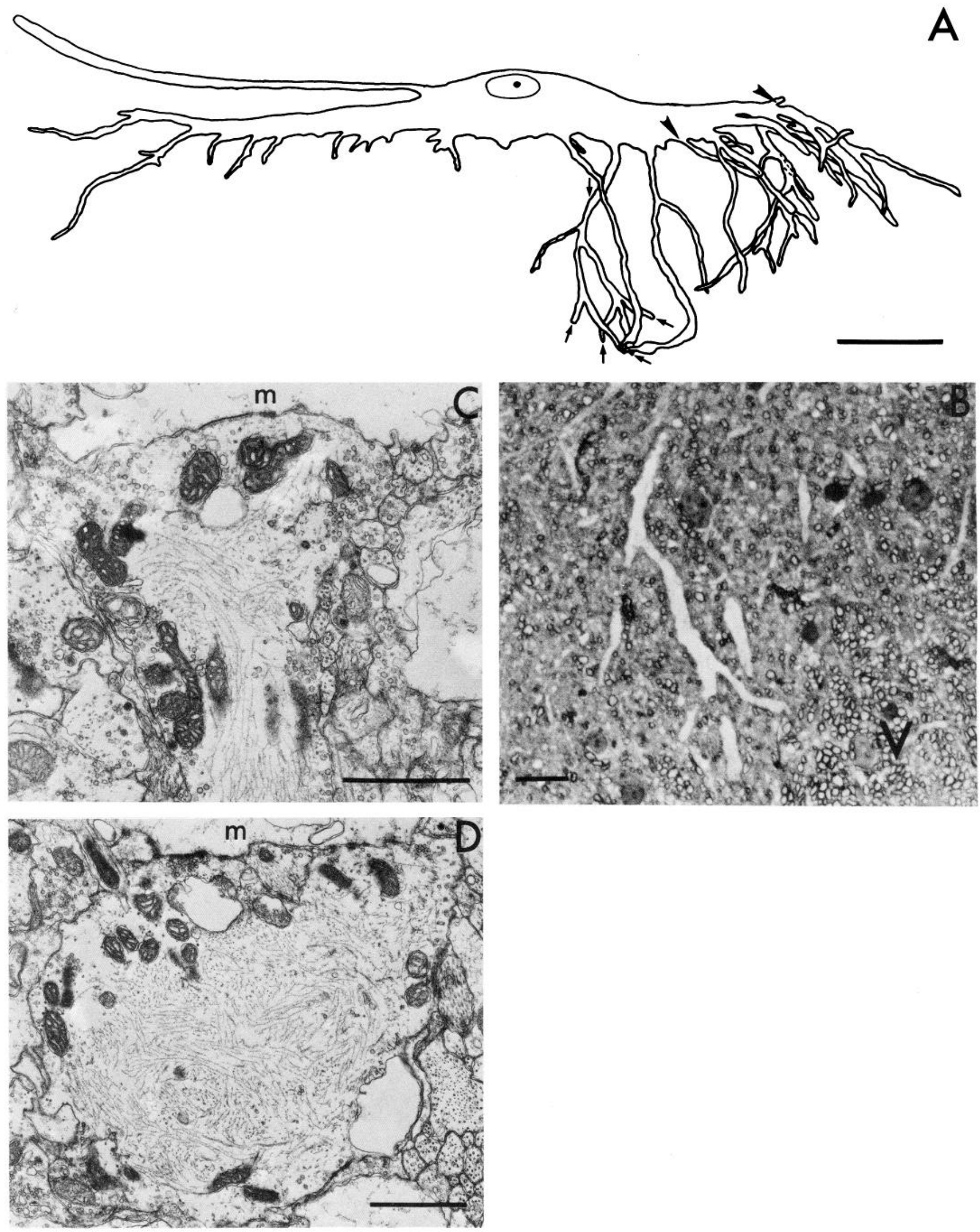

Figure 6. Club endings on displaced dendritic branches. A, Reconstructed experimental M-cell shown in Figure 5B. The arrowheads point to the approximate borders of the nVIII tract. Most of the dendritic branches project into this tract, but some are displaced medially. $B$, Light micrograph of a section through the displaced branches within the arrows in $A . V, \mathrm{nV}$ tract. $C$ and $D$, Club endings found in contact with the displaced dendritic branch shown in $B . m$, M-cell. Scale bar: $A, 100 \mu \mathrm{m} ; B, 20 \mu \mathrm{m} ; C$ and $D, 2 \mu \mathrm{m}$. 
had a substantial loss of dendritic branching in the region that normally receives nVIII synapses (Fig. $4, A-C$ ). Two other deprived M-cells showed a moderate, but significant loss of branching (e.g., Fig. 4D) and one, only a slight loss (not shown). The latter 3 cells were from larvae in which a relatively greater number of nVIII axons had regenerated (e.g., Fig. $3 B$ versus $3 C$ ). The extent of dendritic branching of the $4 \mathrm{M}$-cells in preparations in which there was substantial nVIII regeneration approximated that of their contralateral controls (Fig. 5, $A-D$ ). The reconstructions also revealed that the distribution of dendritic branches on 3 of these experiemntal M-cells was broader than that on control cells (Fig. 5, $B-D$ ). While branches were restricted to the $n$ VIII tract in the control sides, they extended far into adjacent tracts in the experimental sides. Examination of the displaced branches in the electron microscope confirmed that they received vestibular synapses (Fig. 6). Thus, regenerating $\mathrm{nVIII}$ fibers were not always restricted to the nVIII tract.

\section{Discussion}

Unilateral transections of $\mathrm{nVIII}$ results in axonal degeneration and the loss of M-cell dendritic surface in the region that normally receives $n$ VIII synapses (D. A. Covell and P. G. Model, unpublished observations). Here we have shown that when the severed axons regenerate and afferent contacts are reestablished, the postsynaptic dendritic branches recover. If, on the other hand, regeneration of most of the afferents is prevented by destroying ganglion cells, the branching pattern remains atrophic. In larvae with intact ganglia, proof that most of the vestibular axons had regenerated lies in the comparison of the number of axons in the experimental nVIII tract to that in the control: the mean number in the experimental side was $69 \%$ of the control number. That the average number of club endings per section through those experimental M-cells was $72 \%$ of control demonstrates that a majority of the nVIII synapses were restored. In larvae with damaged ganglia, comparison of the nVIII tracts revealed that most of the axons in the experimental side were absent: the mean number was $31 \%$ of control. The corresponding small mean number of club endings per section supports the fact that few afferent contacts were restored in these larvae (overall mean, $31 \%$ of control). Together, the counts of axons and terminals revealed that the average number of restored synapses in both experimental groups was proportional to the mean number of regenerated nVIII axons. The extent of branching on experimental M-cells in the region of nVIII termination is like that of the contralateral controls only in larvae with largely regenerated vestibular nerves. These data indicate that regenerating $\mathrm{nVIII}$ afferents stimulate the growth and recovery of dendritic surface. The observation that most $\mathrm{M}$-cells with restored nVIII input have displaced dendritic branches, and that these branches receive club endings, provides evidence that fibers regenerating outside of the nVIII tract stimulate dendritic growth into aberrant regions of the neuropil.

Two days after nVIII transection in age-matched larvae, Covell and Model (1984) observed that most of the club endings were separated from the M-cell. While vacated postsynaptic sites were not observed, structures suggesting their active uptake by the $\mathrm{M}$-cell were described. The presence of coated pits in M-cell membrane apposed to the detaching terminals and the decrease in area of postsynaptic specialization led the authors to suggest that the target cell itself is responsible for the disappearance of postsynaptic sites by an endocytic mechanism. The present study documents that a specific reduction of post- synaptic surface follows deafferentation and demonstrates that in the absence of regenerating afferent fibers the loss is stable. Comparison of deafferented M-cells to contralateral controls gives one the impression that the disappearance of sites previously occupied by vestibular terminals may not account for the total loss of dendritic surface: Ordinarily, relatively few club endings are interspersed among many other kinds of terminals and the loss of dendritic surface is substantial (i.e., whole branches appear to be absent). We have no data that provide insight into the mechanism of further dendritic loss or the fate of nonvestibular terminals that normally contact the M-cell in this region.

Cut vestibular axons regenerate and reestablish the original pattern of afferent connections on the M-cell (Covell and Model, 1984). They found that regenerating $\mathrm{nVIII}$ axons begin to enter the medulla during the first week after root transection, nVIII fibers contact the $\mathrm{M}$-cell by 2 weeks, and club terminals are present on the appropriate region by 4 weeks. In that study, HRP labeling of vestibular nerves revealed the pattern of the regencrated projection within the medullae: aberrant nVIII fibers (i.e., labeled axons outside of the nVIII tract) were often present. An unexpected finding in the present paper is the broadened dendritic branching pattern of most M-cells receiving regenerated vestibular afferents from intact ganglia. The ectopic branches are, in the main, located medial to the nVIII tract and they do receive vestibular synapses. It is likely that regenerating nVIII axons in aberrant regions of the neuropil induced the growth of the ectopic dendritic branches. Alternatively, the appearance of ectopic branches could have preceded the formation of $n$ VIII contacts. To be in accord with the latter sequence, ectopic branches on M-cells ipsilateral to destroyed ganglia should occur as frequently as they do on M-cells ipsilateral to intact ganglia. There are, however, very few ectopic branches on M-cells ipsilateral to destroyed ganglia. Aberrant nVIII axons presumably occur more frequently in larvae with a large number of regenerating fibers from intact ganglia and thus appear to be required to stimulate the growth of dendritic branches into ectopic areas of neuropil.

Rakic (1972) observed that the configuration of normal Purkinje cell dendritic trees appears to maximize the potential number of afferent contacts. Other investigators have made a similar observation regarding the configuration of denervated dendritic trees: the branches grow into abnormal regions of neuropil, taking on a new configuration that appears to maximize the potential for innervation by appropriate afferents. Deafferentation of spinal cord neurons in kittens results in the disorientation of dendrites such that they project medially toward analogous afferents in the contralateral side (Smith, 1974). In the cricket, dendrites of a deprived interneuron grow aberrantly across the ganglionic midline to form functional synapses with intact contralateral afferents (Hoy et al., 1985). Damaging a specific row of vibrissae in the neonatal mouse redirects the dendritic growth by target cortical neurons toward similar but functional afferent sources (Harris and Woolsey, 1981). In these studies, dendrites are oriented toward afferents analogous to those with which they normally connect. Consistent with this paradigm, the ectopic dendritic branches on the M-cell are oriented toward viable $\mathrm{nVIII}$ afferents as evidenced by the presence of club endings. Although there are nonvestibular synapses present on these branches, in the absence of vestibular afferents, they are apparently not sufficient to induce the growth of the denervated branches, i.e., very few aberrant branches occur on deprived M-cells. Thus, appropriate sources of innervation ap- 
pear to be required to redirect the growth of deafferented dendrites into ectopic locations.

Partial deafferentation reduces dendritic branching specifcally in the region of denervation. For example, Murphey et al. (1975) showed that 2 dendrites of a single neuron in the cricket can be influenced independently if they are innervated by separate sensory organs: Removal of one organ decreased the length of only those branches that were deprived of afferents. Following deafferentation of the ventral dendritic branches of nucleus laminaris neurons in chicks, the resulting dendritic atrophy was restricted to the denervated postsynaptic surface in the ventral neuropil (Benes et al., 1977; Deitch and Rubel, 1984). In accord with those investigations, the loss of M-cell dendritic surface is restricted to the proximoventral region of the lateral dendrite where $\mathrm{nVIII}$ normally connects. The reduced branching pattern of deafferented neurons may be due to slower dendritic growth (Murphey et al., 1975) or degenerative changes (Deitch and Rubel, 1984). In the axolotl, structures suggesting uptake by the M-cell of dendritic membrane provides evidence that active elimination of dendritic surface follows denervation (Covell and Model, 1984). In addition, inhibition of further growth is probably a factor in producing the dramatic difference in the extent of dendritic branching on deprived M-cells.

In the cricket, recovery of dendritic length by giant interneurons occurs after reinnervation (Murphey et al., 1976). That the extent of recovery depends on the length of time allowed for regeneration led the authors to speculate that the degree of reinnervation controls growth of deprived dendrites. Our results support this hypothesis. In larvae with damaged ganglia, a variable fraction of $\mathrm{nVIII}$ axons regenerated and a small number of club endings were restored on the M-cells. The range in extent of dendritic recovery by M-cells ipsilateral to disrupted ganglia appeared to correlate with the degree of nVIII regeneration. These observations are consistent with the notion that each regenerating afferent fiber stimulates a finite amount of dendritic growth.

Not all investigations of deafferented postsynaptic neurons have demonstrated reduced dendritic branching. For example, Tweedle et al. (1973) observed no change in the dendritic tree of an identified neuron in the cockroach after removal of a major source of afferent input. The branching patterns of neurons in adult insects may be more stable than those in young insects (Murphey et al., 1975) or vertebrates. In several studies, investigators have reported that dendritic growth in the rat superior cervical ganglion is largely independent of the presence of preganglionic innervation (McLachlan, 1974; Smolen and Beaston-Wimmer, 1986) and thus that growing dendrites stimulate the formation of new synapses (Voyvodic, 1987). This hypothesis is in conflict with the present study: regenerating vestibular fibers induce recovery of the atrophic postsynaptic dendritic surface. Clearly, nVIII axons regulate the growth and maintenance of specific branches on the M-cell. Furthermore, extra ingrowing nVIII afferents enhance dendritic growth on developing M-cells (Goodman and Model, 1988). The superior cervical ganglion is composed of a heterogeneous population of neurons that requires averaging of dendritic characteristics for analysis. It may be more difficult to observe significant and specific alterations of dendritic branching on heterogeneous neurons compared with homogeneous populations (e.g., nucleus laminaris neurons studied by Deitch and Rubel, 1984) or with identified neurons (e.g., the medial giant interneuron studied by Murphey et al., 1975; the M-cell, present paper). Alternatively,
Voyvodic (1987) suggested that factors influencing the dendritic geometries of neurons in motor systems may be different from those affecting neurons in sensory systems. Similarly, the regulation of branching patterns of central neurons may differ from that of peripheral neurons or that of neurons of different embryonic origin.

nVIII deafferentation of the M-cell results in a reduction of dendritic branches in the region deprived of vestibular contacts. Restoration of the branches occurs only when vestibular axons reestablish contacts on the Mauthner cell. These results indicate that regenerating afferent fibers stimulate postsynaptic dendritic growth. The important finding that displaced dendritic branches receive vestibular synapses implies that regenerating afferent fibers stimulate dendritic growth even in the region outside of the nVIII tract. Afferent innervation is critical in maintaining the postsynaptic dendritic branching pattern of M-cells in mature larvae.

\section{References}

Benes, F. M., T. N. Parks, and E. W. Rubel (1977) Rapid dendritic atrophy following deafferentation: An EM morphometric analysis. Brain Res. 122: 1-13.

Caceres, A., and O. Steward (1983) Dendritic reorganization in the dencrvated dentatc gyrus of the rat following entorhinal cortical lesions: A Golgi and electron microscopic analysis. J. Comp. Neurol. 214: 387-403.

Covell, D. A. (1986) Degeneration and regeneration of the VIIIth cranial nerve in salamander (Ambystoma mexicanum) larvae. Ph.D. dissertation, Albert Einstein College of Medicine, New York.

Covell, D. A., and P. G. Model (1984) Degeneration and regeneration of vestibular axons in axolotl (Ambystoma mexicanum) larvae. Soc. Neurosci. Abstr. 10: 1086.

Deitch, J. S., and E. W. Rubel (1984) Afferent influences on brain stem auditory nuclei of the chicken: Time course and specificity of dendritic atrophy following deafferentation. J. Comp. Neurol. 229: $66-79$.

Goodman, L. A., and P. G. Model (1986) The effect of vestibular ncrve degencration and regeneration on the morphology of the Mauthner cell. Soc. Neurosci. Abstr. 12: 1106.

Goodman, L. A., and P. G. Model (1988) Superinnervation enhances the dendritic branching pattern of the Mauthner cell in the developing axolotl. J. Neurosci. 8: 776-791.

Harris, R. M., and T. A. Woolsey (1981) Dendritic plasticity in mouse barrel cortex following postnatal vibrissa follicle damage. J. Comp. Neurol. 196: 357-376.

Herrick, C. J. (1914) The medulla oblongata of larval Amblystoma. J. Comp. Neurol. 24: 343-427.

Hoy, R. R., T. G. Nolen, and G. C. Casaday (1985) Dendritic sprouting and compensatory synaptogenesis in an identified interneuron follow auditory deprivation in a cricket. Proc. Natl. Acad. Sci. USA 82 . $7772-7776$.

Joncs, W. H., and D. B. Thomas (1962) Changes in the dendritic organization of neurons in the cerebral cortex following deafferentation. J. Anat. 96: 375-381.

Kimmel, C. B., and E. Schabtach (1974) Patterning in synaptic knobs which connect with Mauthner's cell (Ambystoma mexicanum). J. Comp. Neurol. 156: 49-80.

Larsell, O. (1931) The effect of experimental excision of one eye on the development of the optic lobe and opticus layer in larvae of the tree-frog (Hyla regilla). J. Exp. Zool. 58: 1-20.

McLachlan, E. M. (1974) The formation of synapses in mammalian sympathetic ganglia reinnervated with preganglionic or somatic nerves. J. Physiol. (Lond.) 237: 217-242.

Model, P. G. (1978) Aspects of Mauthner cell differentiation in the axolotl, Ambystoma mexicanum. Amer. Zool. 18: 253-265.

Model, P. G., and S. Wurzelmann (1982) Vestibular axons form synapses on abnormally derived Mauthner cells. Dev. Brain Res. 3: 123129.

Morest, D. K. (1969) The growth of dendrites in the mammalian brain. Z. Anat. Entwickl. Gesch. 128: 290-317.

Murphey, R. K., B. Mendenhall, J. Palka, and J. S. Edwards (1975) 
Deafferentation slows the growth of identified giant interneurons. J. Comp. Neurol. 159: 407-418.

Murphey, R. K., S. G. Matsumoto, and B. Mendenhall (1976) Recovery from deafferentation by cricket interneurons after reinnervation by their peripheral field. J. Comp. Neurol. 169: 335-346.

Rakic, P. (1972) Extrinsic cytological determinants of basket and stellate cell dendritic pattern in the cerebellar molecular layer. J. Comp. Neurol. 146: 335-354.

Smith, D. E. (1974) The effect of deafferentation on the postnatal development of Clarke's nucleus in the kitten-a Golgi study. Brain Res. 74: 119-130.

Smolen, A. J., and P. Beaston-Wimmer (1986) Dendritic development in the rat superior cervical ganglion. Dev. Brain Res. 29: 245-252.

Tweedle, C. D., R. M. Pitman, and M. J. Cohen (1973) Dendritic stability of insect central neurons subjected to axotomy and de-afferentation. Brain Res. 60: 471-476.

Voyvodic, J. T. (1987) Development and regulation of dendrites in the rat superior cervical ganglion. J. Neurosci. 7: 904-912. 